\title{
Effects of partial delay of reinforcement following a small number of acquisition trials
}

\section{J. CLIVE HOWLETT AND M. H. SHELDON, DEPARTMENT OF PSYCHOLOGY, HULL UNIVERSITY, Hull, England}

Rats trained in a runway received nine extinction trials immediately after three acquisition trials. For one group of animals reinforcement during acquisition was always given immediately; for another group it was immediate on one trial, but delayed on two. The second group of animals ran faster during extinction.

McCain (1966) has shown in a number of experiments that after even a small number of acquisition trials (as few as two) intermittent reinforcement is followed by slower extinction than continuous reinforcement is. Using a large number of acquisition trials, Wike \& McNamara (1957) found differences in extinction associated with partial delay of reinforcement, a procedure in which reinforcement is delayed on some proportion of trials. Delay on 50 or $75 \%$ of acquisition trials led to slower extinction than delay on $25 \%$. Using only five acquisition trials, McCain \& Bowen (1967) compared the effects of immediate reinforcement with those of reinforcement delayed on every trial, and found differences in extinction. The following experiment was carried out to see whether any effect of partial delay of reinforcement could be found with a small number of acquisition trials.

Method. Testing was carried out in a straight runway, 13 in. high, 4 in. wide, and 46 in. long, this length including a start box and a goal box both 7 in. long. The start box and the goal box could both be separated from the rest of the runway by guillotine doors, and the goal box contained a food cup into which $48 \mathrm{mg}$ sugar pellets could be delivered individually from a mechanical feeder. The doors and the feeder were operated by $E$ from his position behind the start box. The runway was made of wood and painted medium grey. The only light in the experimental room came from a $15 \mathrm{~W}$ bulb above the goal box.

The Ss were 40 hooded rats ( 20 male and 20 female) bred in the laboratory; they were about 120 days old. They were placed on a $23 \mathrm{~h}$ food deprivation schedule (with water always available) on Day 1 , and this remained in force throughout the experiment. Pretraining was carried out on Days 5 and 6: Ss were placed individually in the goal box with the door shut, and on each day the feeder was operated to deliver 15 pellets. It was not operated when $\mathbf{S}$ was directly investigating the food cup, and at least $30 \mathrm{sec}$ had to elapse between successive deliveries. The time between the click of the feeder and S's taking the pellet was recorded for the last five deliveries on Day 6, and Ss were divided into two groups matched for the mean value of these five time scores.

On Day 7 all Ss were given three acquisition trials and nine extinction trials in the runway. A $S$ was placed in the start box, and after $15 \mathrm{sec}$ the door was opened whenever $S$ faced towards it. When $S$ entered the goal box the door was closed behind it. For members of one group of animals a single pellet of food was delivered as soon as the door was closed on each of the three acquisition trials. For members of the other group delivery was delayed by 60 sec on Trials 1 and 3. All Ss remained in the goal box for $5 \mathrm{sec}$ after the delivery of a pellet, and were then immediately returned to the start box for another trial. For each $\mathbf{S}$ extinction followed acquisition without interruption. No reinforcement was given, and $S$ was left in the empty goal box for $5 \mathrm{sec}$. On all trials the interval between the opening of the start box and the closing of the goal box door was recorded. The Ss were pretrained and trained in batches of 10, one batch each week for four successive weeks. Within each batch all Ss were of the same sex, and equal numbers served under each of the reinforcement conditions.

Results. Analyses of variance for the effects of reinforcement condition, trials, and sex were computed for the three acquisition trials taken together with the first extinction trial (referred to as "acquisition") and for the last eight extinction trials (referred to as "extinction"). In acquisition running speed was not significantly affected by reinforcement condition $(F<1)$. There was variation over trials $(F=3.49, \mathrm{df}=3 / 144, \mathrm{p}<.025)$ and between sexes, females running faster than males $(F=5.45$, $d f=1 / 144, p<$ $.025)$. None of the interactions was significant. In extinction the effect of reinforcement condition was significant $(F=9.82$, df $=$ $1 / 288, \mathrm{p}<.01)$. There was variation over trials $(\mathrm{F}=2.16$, $\mathrm{df}=$ $7 / 288, \mathrm{p}<.05)$, and again females ran faster than males $(F=$ $26.87, \mathrm{~d} f=1 / 288, p<.001)$. The only significant interaction was that of reinforcement condition with sex $(F=6.13, \mathrm{df}=1 / 288, p$ $<.025$ ).

In addition, the effects of reinforcement condition and trials, first in acquisition and then in extinction, were analyzed separately for males and females. During acquisition only the effect of trials was significant for females $(F=3.12$, df $=3 / 72, p<.05)$. For males there were no significant effects. During extinction the only significant effect was that of reinforcement condition: for females $F=9.08, \mathrm{df}=1 / 144, \mathrm{p}<.01$; for males $F=5.16, \mathrm{df}=$ $1 / 144, \mathrm{p}<.025$.

Discussion. With large numbers of acquisition trials, partial delay of reinforcement and intermittent reinforcement have similar effects on extinction. The results of this experiment, taken together with those of McCain (1966) suggest that the same may be true when exposure to the acquisition conditions is very brief. It should be noticed that in the present experiment males and females were affected differently by the acquisition conditions; in earlier experiments (McCain, 1966; McCain \& Bowen, 1967), when males and females were both used their results were not treated separately.

\section{REFERENCES}

McCAIN, G. Partial reinforcement effects following a small number of acquisition trials. Psychon. Monogr. Suppl., 1966, 1, 251-270.

McCAIN, G., \& BOWEN, J. Pre- and postreinforcement delay with a small number of acquisition trials. Psychon. Sci., 1967, 7, 121-122.

WIKE, E. L., \& McNAMARA, H. J. The effects of percentage of partially delayed reinforcement on the acquisition and extinction of an instrumental response. J. comp. physiol. Psychol, 1957, 50, 348-351. 